\section{TÀI LIÊU THAM KHẢO}

1. Đào Xuân Thành (2012) "Nghiên cứu kết quả thay khớp háng toàn phần không xi măng và thay đổi mật độ xương quanh khớp háng nhân tạo" Luận văn tiến sĩ y học.

2. Đoàn Việt Quân (2010) "Thay lại khớp háng nhân tạo bằng khớp háng có xi măng nhân 23 trường hợ". y hoc thức hành só $6 / 2013$.

3. Christopher M. Haydon, "Revision Total Hip Arthroplasty with Use of a Cemented Femoral
Component. Results at a Mean of Ten Years" ] Bone Joint Surg Am. 2004;86:1179-1185.

4. M. Røkkum, M. Brandt, "Polyethylene wear, osteolysis and acetabular loosening with an HAcoated hip prosthesis" ] Bone Joint Surg [Br] 1999;81-B:582-9.

5. Merle d'Aubigné R. (1970), "Cotation chiffrée de la fonction de la hanche". Rev Chir Ortho Reparatrice Appar Mot, 56 (5), pp 481-86.

\title{
KHẢO SÁT CHẤT ƯợNG CUỘC SỐNG CỦA NGƯờI BỆNH XƠ GAN KHÁM VÀ ĐIỀU TRI TẠI BỆNH VIỆN ĐA KHOA XANH PÔN
}

\section{TÓM TẮT}

Mục tiêu: Mô tả chất lượng cuộc sống của người bênh xơ gan tai bênh viên đa khoa Xanh Pôn năm 2020. Phương pháp nghiên cứu: mô tả cắt ngang có phân tích trên 80 người bênh xơ gan đến khám và điều trị tại phòng khám tiêu hóa và khoa nội 2 bệnh viên đa khoa Xanh Pôn trong tháng 5 năm 2020. Kết quả: nghiên cứu cho thấy người bệnh trên 60 tuổi chiếm tỷ lệ cao nhất $46.3 \%(37 / 80)$, nam giới chiếm ưu thế $65 \%(52 / 80)$, người bệnh về hưu và sống ở Hà Nôi lần lượt chiếm ưu thế lần lướt là $51,3 \%(41 / 80)$ và $83.8 \%(67 / 80)$. Đa số người bệnh có tiền sử về sư dung rươu và thuốc lá chiếm tỷ lệ lần lướt $57.5 \%$ và $52.5 \%$. Nguyên nhân gây xơ gan cho người bệnh chủ yếu do viêm Gan B 73.8\%(59/80). Điểm trung bình CLCS chung của người bệnh xơ gan thấp 4.71(SD $= \pm$ $0,69)$, với $\min 2,9$ và max 6 . Trong đó điểm CLCS trung bình của phần triệu chứng ở ổ bụng, đạt 4,29 ( $\mathrm{SD}= \pm 1,17)$, điểm CLCS trung bình của phần mệt mỏi đạt 4,26 (SD = $\pm 0,94)$, điểm CLCS trung bình của phần triệu chứng toàn thân đạt 4,51 (SD $= \pm$ $0,75)$, điểm CLCS trung bình của phần hoat động đạt $4,63$ ( $S D= \pm 0,98)$, điểm CLCS trung bình của phần chức năng cảm xúc đat $4,81(\mathrm{SD}= \pm 0,78)$, cuối cùng là điểm CLCS trung bình của phần lo lắng cao 5,49 $(S D= \pm 3,31)$. Kết luân: Bênh xơ gan ảnh hưởng đến CLCS của người bệnh đặc biệt tình trạng mệt mói của người bệnh bị ảnh hưởng nhiều nhất.

\section{SUMMARY \\ QUALITY OF LIFE AMONG PATIENTS WITH CIRRHOSIS AND FACTORS RELATED TO QUALYTY OF LIFE \\ Objective: Descriptive quality of life and factors} related to quality of life among patients with Cirrhosis at Saint Paul General Hospital in 2020.Research

*Trường Đại học kỹ thuật y tế Hải Dương Chiu trách nhiếm chính: Phạm Thị Thanh Phương Email: phuonghmtu@gmail.com Ngày nhận bài: 4.5.2021

Ngày phản biên khoa học: 24.6.2021

Ngày duyệt bài: 6.7.2021

\section{Phạm Thị Thanh Phương*, Nguyễn Thị Nga*}

method: A cross-sectional description with analysis on 80 patients with cirrhosis who came for examination and treatment at the gastroenterology clinic and internal medicine department at Saint Paul General Hospital in May 2020. Research result: The study showed that patients over 60 years old accounted for the highest proportion $46.3 \%$ (37/80), male dominated with $65 \%(52 / 80)$, the majority were retirees and lived in Hanoi, respectively, accounting for $51.3 \%(41 / 80)$ and $83.8 \%(67 / 80)$. The majority of patients had a history of alcohol and tobacco use, accounting for $57.5 \%$ and $52.5 \%$, respectively. Most of the patients with cirrhosis are caused by hepatitis B $73.8 \%(59 / 80)$. The average QOL score of patients with cirrhosis is low $4.71(\mathrm{SD}= \pm 0.69)(<5)$, with min 2.9 and max 6. In which, the average QOL score of the symptomatic part of the abdomen reached 4.29 $(\mathrm{SD}= \pm 1.17)$, the average QOL score of the fatigue section reached $4.26(\mathrm{SD}= \pm 0.94)$, the average QOL score of the fatigue section reached 4.26 (SD $= \pm$ 0.94). The mean QOL score of the systemic symptoms part reached $4.51(\mathrm{SD}= \pm 0.75)$, the mean QOL score of the activity part reached $4.63(\mathrm{SD}= \pm 0.98)$, the mean QOL score of the sensory function section exposure reached 4.81 ( $S D= \pm 0.78$ ). Finally, the mean QOL score of the anxiety section reached 5.49 $(\mathrm{SD}= \pm 3.31)$. Conclusion: Cirrhosis affects the patient's QOL, especially fatigue is the most effect.

\section{I. ĐĂT VẤN ĐỀ}

Trong năm 2017, xơ gan đã gây ra hơn 1,32 triệu ca tử vong. Trong đó 440.000 người chiếm $33.3 \%$ là nữ và 883.000 người chiếm $66,7 \%$ là nam trên toàn câu.Tử vong do xớ gan chiếm $2,4 \%$ trong tổng số tử vong trên toàn cầu năm 2017. Có 10,6 triệu các trường hợp bị xơ gan mất bù và 112 triệu trường hợp bị xơ gan còn bù trong năm 2017 [5]. Ở Việt Nam năm 2016 tỷ lệ tử vong do xơ gan ở nam chiếm tỷ lệ 44,5 / 100000 dân/năm và $8,6 / 100000$ dân/năm ở nữ. [6]

Xơ gan là giai đoạn cuối của các bệnh về gan mật mạn tính. Người bệnh xơ gan ảnh hưởng tiêu 
cực đến chất lượng cuộc sống của người bệnh vì người bệnh thường bị mệt mỏi, gầy sút cân, chán ăn, suy dinh dưỡng, rối loạn tiêu hóa, táo bón đau bụng, phù chân, cổ trướng, xuất huyết tiêu hóa.[3]. Hơn nữa, bệnh xơ gan làm ảnh hưởng đến vấn đề thể chất, mối quan hệ xã hội, suy giảm chức năng, thay đổi tâm trạng, lo lắng, trâm cảm, năng suất lao động giảm sút và các vấn đề cảm xúc khác ảnh hưởng nghiêm trọng đến chất lượng cuộc sống và hạnh phúc của người bệnh.[4]. Chất lượng cuộc sống" (CLCS) liên quan đến sức khỏe" là những ảnh hưởng do một bệnh, tật hoặc một rối loạn sức khỏe của một cá nhân đến sự thoải mái và khả năng hưởng thụ cuộc sống của cá nhân đó. Ngày nay, để đo lường kết quả điều trị người ta sử dụng khái niệm "kết quả" (outcome) trong đó chất lượng cuộc sống cũng là một kết quả của điều trị, đặc biệt trong các bệnh mạn tính vì ít nhiêu gây ảnh hưởng lên CLCS của bệnh người bệnh (NB).

Nghiên cứu về CLCS cung cấp cho người bệnh thêm thông tin về quá trình diễn tiến của bệnh cũng như tình trạng sức khỏe trong quá trình điều trị, qua đó giúp ho cân nhắc giữa các phương pháp điều trị khác nhau, đồng thời giúp người bệnh cải thiện khả năng thích nghi và hòa nhập với cuộc sống trong quá trình điều trị. [1]

Từ trước đến nay, trên thế giới cũng đã có nghiên cứu về chất lượng cuộc sống của người bệnh mắc bệnh gan mạn tính như Nhật Bản, Brazi [4]. Ở Việt Nam đã có nhiều nghiên cứu trước đây về xớ gan, nhưng chủ yếu tập trung vào dịch tễ học, chẩn đoán, điều trị còn nghiên cứu về chất lượng cuộc sống của người bệnh xơ gan còn hạn chế. và từ trước đến nay tại bệnh viện đa khoa Xanh Pôn chưa có đề tài nghiên cứu về chất lượng cuộc sống của người bệnh xơ gan. Vì vậy em tiến hành nghiên cứu đề tài: "Khảo sát chất lượng cuộc sống của người bệnh Xơ gan tại bệnh viện đa khoa Xanh Pôn năm 2020". Mục tiêu nghiên cứu: Mô tả chất lượng cuộc sông của người bệnh xơ gan tại bệnh viện đa khoa Xanh Pôn năm 2020.

\section{KẾT QUẢ NGHIÊN CỨU}

\section{Bảng 3.1. Đặc điểm về tuổi, giới của đôi tượng nghiên cứu}

\begin{tabular}{|c|c|c|c|c|c|}
\hline \multirow{2}{*}{ Tuổi Giới tính } & \multicolumn{2}{|c|}{ Nam } & \multicolumn{2}{|c|}{ Nũ̃ } & \multirow{2}{*}{ Tỷ lệ\% } \\
\cline { 2 - 5 } & $\mathbf{n}$ & $\mathbf{\%}$ & $\mathbf{n}$ & $\mathbf{\%}$ & \\
\hline$<=40$ & 3 & 75 & 1 & 25 & 5 \\
\hline $41-50$ & 15 & 83,3 & 3 & 16,7 & 22,5 \\
\hline $51-60$ & 15 & 71,4 & 6 & 28,6 & 26,2 \\
\hline$>60$ & 19 & 51,4 & 18 & 48,6 & 46,3 \\
\hline Tống & 52 & 100 & 28 & 100 & 100 \\
\hline
\end{tabular}

II. ĐỐI TƯợNG VÀ PHƯƠNG PHÁP NGHIÊN CứU

2.1. Đối tượng nghiên cứu: Người bệnh xơ gan đến khám và điều trị tại Bệnh viện đa khoa Xanh pôn

\section{- Tiêu chuẩn lựa chon}

+ Người bệnh được chẩn đoán xơ gan ít nhất 1 tháng trước đó.

+ Người bệnh tự nguyện tham gia vào nghiên cứu.

+ Người bệnh có khả năng giao tiếp (nghe, nói, đọc, viết).

+ Người bênh từ 18 tuổi trở lên.

- Tiêu chuẩn loại trừ

+ Người bệnh có bệnh lý cấp tính, dấu hiệu sinh tồn không ổn định.

+ Người bệnh không trả lời hết bộ câu hỏi

+ Người bệnh mắc bệnh xơ gan kèm một số bệnh sau: tâm thần, câm điếc, sa sút trí tuệ.

\subsection{Phương pháp nghiên cứu}

- Thiết kế nghiên cứu: Nghiên cứu mô tả cắt ngang

- Cõ mẫu: 80 người bệnh đến khám và điều trị bệnh xơ gan tại Bệnh viện đa khoa Xanh pôn trong tháng 5 năm 2020 và đáp ứng các tiêu chuẩn lựa chọn của nghiên cứu.

- Phương pháp thu thập số liệu: Phỏng vấn trực tiếp người bệnh đang điều trị tại khoa nội 2 và người bệnh ngồi chờ khám, chờ kết quả xét nghiệm tại phòng khám tiêu hóa bằng cách sử dụng một bộ câu hỏi được chia thành 2 phần gồm: Đặc điểm của người bệnh, câu hỏi CLCS.

- Phương pháp phân tích số liệu

+ Số liệu sau khi kiểm tra được nhập liệu và xử lý bằng phần mềm SPSS 20.0.

+ Sử dụng tần số và tỷ lệ phần trăm để mô tả các đặc điểm chung của NB, sử dụng giá trị min, max, mean, tỷ lệ phần trăm, tần số để mô tả chất lượng cuộc sống của người bệnh xơ gan. Mọi sự khác biệt được xem là có ý nghĩa thống kể khi $p<0,05$ với khoảng tin cậy 95\%.

+ Chỉ số tương quan Pearson được sử dụng để mô tả mối tương quan giữa CLCS với một số đặc điểm của đối tượng nghiên cứu. 
Nhận xét: Đa số người bệnh xơ gan tham gia nghiên cứu thuộc nhóm trên 60 tuổi gồm 37 người chiếm tỉ lệ 46,3\%. Tỷ lệ nam giới mắc bệnh xơ gan cao hơn nữ giới chiếm 52/8051\% người bệnh đến khám(65\%).

Bảng 3.2. Đặc điểm về nghề nghiệp và vùng sinh sống

\begin{tabular}{|c|c|c|c|}
\hline \multicolumn{2}{|c|}{ Đặc điểm } & $\begin{array}{c}\text { Tân } \\
\text { số(n) }\end{array}$ & $\begin{array}{c}\text { Tỷ } \\
\text { Iệ\% }\end{array}$ \\
\hline \multirow{4}{*}{$\begin{array}{c}\text { Nghề } \\
\text { nghiệp }\end{array}$} & Về hưu & 41 & 51,3 \\
\cline { 2 - 4 } & Nông dân & 6 & 7,5 \\
\cline { 2 - 4 } & $\begin{array}{c}\text { Công nhân (tư } \\
\text { nhân, nhà nước) }\end{array}$ & 14 & 17,5 \\
\cline { 2 - 4 } & Cán bộ viên chức & 2 & 2,5 \\
\cline { 2 - 4 } & Nông dân & 6 & 7,5 \\
\cline { 2 - 4 } & Nội trợ & 11 & 13,7 \\
\hline \multirow{4}{*}{$\begin{array}{c}\text { Khu vự } \\
\text { sinh sống }\end{array}$} & Thành thị & 67 & 83,8 \\
\cline { 2 - 4 } & Nông thôn & 13 & 16,2 \\
\hline
\end{tabular}

Nhận xét: Phần lớn người bệnh xơ gan đều sống tại thành phố Hà Nội gồm có 67 người chiếm tỉ lệ $83,8 \%$ và hơn một nửa số người bệnh tham gia nghiên cứu đã về hưu $(51,3 \%)$.

Bảng 3.3. Thu nhập cá nhân và việc sử dụng bảo hiểm Y tế của đối tượng nghiên cúlu

\begin{tabular}{|c|c|c|c|}
\hline \multicolumn{2}{|c|}{ Đặc điểm } & Tân số & Tỷ lệ \\
\hline \multirow{2}{*}{$\begin{array}{c}\text { Thu } \\
\text { nhâpp cá } \\
\text { nhîan }\end{array}$} & Không có thu nhập & 14 & 17,5 \\
\cline { 2 - 4 } & Dưới 1 triệu & 1 & 1,2 \\
\cline { 2 - 4 } & Từ 1 đến 3 triệu & 39 & 48,8 \\
\cline { 2 - 4 } & Từ 3 triệu trở lên & 26 & 32,5 \\
\hline \multirow{2}{*}{$\begin{array}{c}\text { Bảo hiểm } \\
\text { y tế }\end{array}$} & Có & 80 & 100 \\
\cline { 2 - 4 } & Không & 0 & 0 \\
\hline
\end{tabular}

Nhận xét: $82,5 \%$ người bệnh xơ gan tham gia nghiên cứu có thu nhập cá nhân, trong đó gần một nửa $(48,8 \%)$ người bệnh có thu nhâap từ môt đến 3 triêu. $32,5 \%$ người bênh có thu nhập từ 3 triệu trở lên, chỉ 1 người có thu nhập dưới 1 triệu là tiền trợ cấp xã hội. Còn lại 17,5 \% người bệnh không có thu nhập cá nhẩn. 100\% người bệnh tham gia vào nghiên cứu đều tham gia bảo hiểm y tế.

Bảng 3.4. Thời gian phát hiênn và giai đoạn bệnh xơ gan của đôî tượng nghiên cứu

\begin{tabular}{|c|c|c|c|}
\hline \multicolumn{2}{|c|}{ Đặc điểm } & $\begin{array}{l}\text { Tân } \\
\text { số }\end{array}$ & Tỷ lệ \\
\hline \multirow{3}{*}{$\begin{array}{l}\text { Khoảng } \\
\text { thời gian } \\
\text { chẩn đoán } \\
\text { là xơ gan }\end{array}$} & $\begin{array}{c}\text { Từ } 1 \text { tháng đến < } \\
1 \text { năm }\end{array}$ & 45 & 56,2 \\
\hline & 1-2 năm & 19 & 23,8 \\
\hline & >2 năm & 16 & 20 \\
\hline \multirow{2}{*}{$\begin{array}{l}\text { Giai đoạn } \\
\text { của bệnh }\end{array}$} & Xơ gan còn bù & 72 & 90 \\
\hline & Xơ gan mất bù & 8 & 10 \\
\hline
\end{tabular}

Nhận xét: Người bênh tham gia nghiên cứu được chẩn đoán xơ gan trong thời gian từ 1 tháng đến dưới một năm là 45 người chiếm tỉ lệ $56,2 \%$.

Bảng 3.5. Thói quen sử dụng thuốc lá, rươu bia

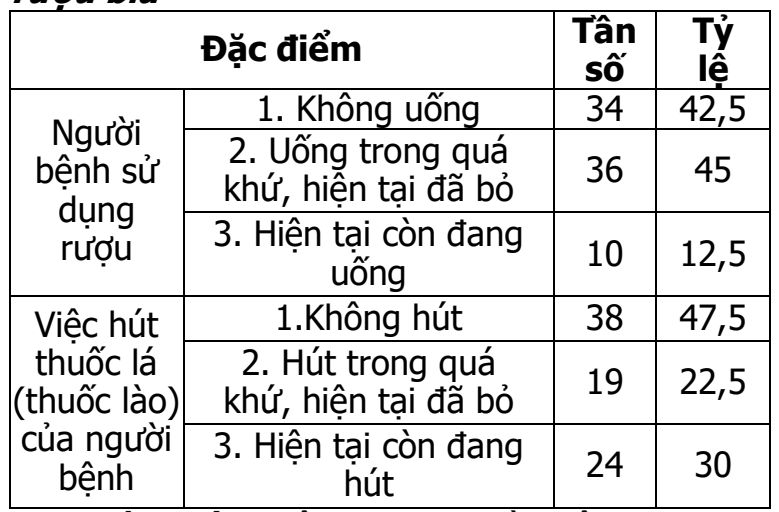

Nhận xét: Trên 40\% người bệnh xơ gan tham gia nghiên cứu không sử dụng rượu bia. Trên $50 \%$ người bệnh tham gia nghiên cứu có sử dụng rượu bia, trong đó $45 \%$ người tham gia đã bỏ rượu và $12,5 \%$ người tham gia nghiên cứu vẫn đang sử dụng rượu bia.

Bảng 3.6. Chât lượng cuộc sống của người bệnh xơ gan sử dụng bộ câu hỏi Chronic Liver Disease Questionnaire (CLDQ)

\begin{tabular}{|c|c|c|c|c|c|}
\hline Chất lượng cuộc sống của người bệnh xơ gan & Min & Max & Mean & SD & $\begin{array}{c}\text { Mức } \\
\text { đô }\end{array}$ \\
\hline Tống điếm chung của chất lượng cuộc sống & 2,9 & 6 & 4,71 & 0,69 & Thấp \\
\hline - Điếm chất lương cuốc sống trong phân triêu chứng ở ố bung & 1 & 6 & 4,29 & 1,17 & Thấp \\
\hline - Điếm CLCS trong phần Mệt mỏi & 2 & 6 & 4,26 & 0,94 & Thấp \\
\hline - Điếm CLCS cho phần triếu chứng toàn thân & 2,8 & 6 & 4,51 & 0,75 & Thấp \\
\hline - Điếm CLCS cho phần hoạt động & 2,67 & 6 & 4,63 & 0,98 & Thấp \\
\hline - Điểm CLCS cho phần chức năng cảm xúc & 2,25 & 6 & 4,81 & 0,78 & Thấp \\
\hline - Điếm CLCS cho phân lo lắng & 3,8 & 6,4 & 5,49 & 0,66 & Cao \\
\hline
\end{tabular}

Nhận xét: Điểm CLCS trung bình cho toàn bộ câu hỏi và các đối tượng nghiên cứu là 4,71 (SD = $\pm 0,69)$. Có nghĩa là CLCS chung của người bệnh xơ gan còn chưa cao $(<5)$. Nhưng điểm về lo lắng có giá trị trung bình là $5,49(\mathrm{SD}= \pm 0,66)$ có nghĩa là người bệnh bị xơ gan ít gặp vấn đề lo lắng. 


\section{BÀN LUẬN}

4.1. Thực trạng mắc bênh xơ gan ở người bệnh đến khám và điều trị tại bệnh viện Xanhpon. Kết quả nghiên cứu cho thấy đối tượng nghiên cứu mắc bệnh xơ gan đa số rơi vào độ tuổi trên 60 và nam giới mắc bênh hơn nữ giới. Điều này có thể giải thích được là do đối tượng nghiên cứu chiếm $51 \%$ là cán bộ nghỉ hưu và $83.8 \%$ ở thành thì thị nên họ có thời gian cũng khoảng cách di chuyển đến bệnh viện Xanhpon khám sức khoẻ thuận tiện hớn so với đối tượng đang trong độ tuổi lao động và ở khu vực nổng thôn. Kết quả nghiên cứu này có sự khác biệt một phần với nghiên cứu của tác giả Om Parkask và cộng sự tại bệnh viện đại học chăm sóc Pakistan trên 273 NB thì nhóm tuổi từ 60 trở lên chiếm $12,5 \%$, trong nghiên cứu này độ tuổi từ 41-50 chiếm cao nhất đạt $35,1 \%$. Nam giới chiếm tỷ lệ $57 \%$ tương đương với nghiên cứu hiện tại và nội trợ chiếm tỷ lệ cao nhất 39\%, NB nghỉ hưu ít hơn so với nghiên cứu tại BV Đa khoa Xanh Pôn là 11\% [2]. Còn so với nghiên cứu trên 133 người bệnh tại Brazin thì thì tỷ lệ giới gần giống với nghiên cứu tại $\mathrm{BV}$ Đa Khoa Xanh Pôn là $66,2 \%$ là nam giới, độ tuổi lớn hơn 60 chiếm 23,3\%, phần lớn nghề nghiệp của người bệnh là nhân viên $42,9 \%$, nội trợ chỉ chiếm $7,5 \%$ và nghỉ hưu chiếm $27,8 \%[4]$. Tình trang người bênh mắc bênh xơ gan ở giai đoan còn bù chiếm tỷ lệ cao chiếm $90 \%$ với kết quả này rất phù hợp với thời gian người bệnh phát hiện bệnh vì đa số đới tượng nghiên cứu được phát hiên bênh cách thời điểm nghiên cứu từ 1tháng đến < 1 năm (56.2\%). Kết quả này khác với nghiên cứu tại Pakistan có $66 \%$ là xơ gan còn bù, $34 \%$ ở giai đoạn mất bù. [2] Còn nghiên cứu tại Brazil 93,2\% ở giai đoạn xơ gan mất bù có cổ chướng. [4]

4.2 Chất lượng cuộc sống của NB xơ gan tham gia nghiển cứu theo bộ câu hỏi CLDQ.

* Điểm CLCS chung của người bệnh:

Điểm trung bình CLCS của người bệnh xơ gan trong nghiên cứu thấp $4,71(S D= \pm 0,69)$, với $\min 2,9$ và $\max 6$ và tổng điêm CLCS là 136,57 $(S D= \pm 20,04)$ với min 84 và max 174. Điều này có thể giải thích được vì bệnh xơ gan là bệnh mạn tính đòi hỏi thời gian điều trị kéo dài nên kinh phí để điều tri bênh này cũng như tiên đi lại rất tốn kém. Hơn $1 / 2$ người bệnh là cán bộ nghỉ hưu $(51.3 \%)$ họ không đủ sức lao động để có thể kiếm thêm tiền ngoài khoản tiền lương tháng, và thực tế thu nhập của họ đa số $\leq 3$ triệu/ tháng $(60.8 \%)$ và có tới $17.5 \%$ là không có thu nhập. Với mức thu nhập như thế này cộng với địa điểm sống của đối tượng nghiên cứu chủ yếu ở thành thị (83.8\%) giá cả mọi thứ đáp ứng nhu cầu cuộc sống cơ bản của người dân rất cao so với ở vùng nông thôn. Đây là những lý do có thể làm cho chất lượng cuộc sống của người bệnh xơ gan kém đi. Nhưng điểm số này cao hớn so với nghiên cứu trên trên 273 người bệnh tại Pakistan cho kết quả điểm trung bình $\mathrm{CLCS}$ là $4,36(\mathrm{SD}= \pm 1,15)$ min 1,3 và max 6,98. Tổng điểm CLCS là 126,54 (SD $= \pm$ $32,97)$ với min 38 và max 202. [2]

Điểm các thành phần chất lượng cuộc sống: Đầu tiên là điểm CLCS trung bình của phần triệu chứng ở ổ bụng, đạt 4,29 (SD = = $1,17) \min 1$ và max 6 và tổng điểm CLCS là $12,89$ (SD $= \pm 3,5)$ thấp hơn so với nghiên cứu tại Pakistan đạt 4,48 (SD 1,71) với min 1 và max 7 và tổng điểm $\mathrm{CLCS}$ là $13,47(\mathrm{SD}= \pm 5,14)$. Còn nghiên cứu của tai Brazil năm 2012 cũng cao hơn nhiêuu có tổng điểm CLCS là 16 ( $\mathrm{SD}= \pm$ 6,25).[4]

Thứ hai là điểm CLCS trung bình của phần mệt mỏi đạt 4,26 $(S D= \pm 0,94) \min 2$ và $\max 6$ và tổng điểm CLCS là 21,33 (SD $= \pm 4,69)$ cao hơn so với nghiên cứu tại Pakistan đạt 3,85 (SD $= \pm 1,27)$ với $\min 1$ và $\max 7$ và tổng điểm CLCS là 19,26 $(S D= \pm 6,3)$. Nghiên cứu của tại Brazil năm 2012 cũng cao hơn có tổng điểm CLCS là 23,35 (SD $= \pm 9,32$ ).

Thứ 3 là điểm CLCS trung bình của phần triêuu chứng toàn thân đạt $4,51(\mathrm{SD}= \pm 0,75) \min 2,8$ và max 6 và tổng điểm CLCS là 22,54 (SD $= \pm$ $3,75)$ cao hơn so với nghiên cứu tại Pakistan đạt $4,19(\mathrm{SD}= \pm 1,29)$ với $\min 1$ và max 7 và tổng điểm CLCS là 20,98 (SD = $\pm 6,47)$.[2] Và thấp hơn so với nghiên cứu của tại Brazil năm 2012 có tổng điểm CLCS là 27,29 (SD = 6,76).[4]

Thứ 4 điểm CLCS trung bình của phân hoạt động đạt $4,63(S D= \pm 0,98) \min 2,67$ và $\max 6$ và tổng điểm CLCS là $13,88(\mathrm{SD}= \pm 2,95)$ cao hơn so với nghiên cứu tại Pakistan đạt 4,38 (SD $= \pm 1,75)$ với $\min 1$ và $\max 7$ và tổng điểm $C L C S$ là $13,14(S D= \pm 5,14)$. Và thấp hơn so với nghiên cứu của tại Brazil năm 2012 có tổng điểm CLCS là 16,45 (SD = 5,19). [4]

Thứ 5 điểm CLCS trung bình của phần chức năng cảm xúc đạt $4,81(S D= \pm 0,78) \min 2,25$ và max 6 và tổng điểm CLCS là $38,53(S D= \pm$ $6,27)$ cao hơn so với nghiên cứu tại Pakistan đạt $4,47(S D= \pm 1,38)$ với $\min 1$ và max 7 và tổng điểm CLCS là 35,76 (SD 1= 11,08).[2] Và thấp hơn so với nghiên cứu của tại Brazil năm 2012 có tổng điểm CLCS là 39,7 (SD = 12,98$)$.[4]

Cuối cùng, là điểm CLCS trung bình của phần 
lo lắng đạt $5,49(S D= \pm 3,31)$ min 3,8 và $\max 6$ và tổng điểm CLCS là 27,43 $(\mathrm{SD}= \pm 3,31)$ cao hơn so với nghiên cứu tại Pakistan đạt 4,78 (SD $= \pm 1,75)$ với min 1 và max 7 và tổng điểm $C L C S$ là 23,92 (SD = =7,68).[2] Và thấp hơn so với nghiên cứu của tại Brazil năm 2012 có tổng điểm CLCS là 25,69 (SD = =9,99).[4]

\section{KẾT LUÂ̂N}

Điểm trung bình CLCS của người bệnh xơ gan trong nghiên cứu là 4,71 (SD = 00,69$)$. Đặc biệt dấu mệt mỏi của người bệnh xơ gan cần phải được quản lý chặt chẽ hơn vì trong nghiên cứu này điểm số mệt mỏi thấp nhất trong các thành phần điểm của chất lượng cuộc sống người bệnh $x \widetilde{o}$ gan (Mean $=4,26 ; \dot{S D}= \pm 0,94$ ).

\section{TÀI LIÊU THAM KHẢO}

1. Bùi Thế Anh, (2019). "Đánh giá chất lượng cuộc sống của người bệnh ung thư thanh quản trước và sau phẩu thuật", Luận án tiến sỹ y học, Đại học Y Hà Nội.

2. Parkash, O., Iqbal, R., Jafri, F., Azam, I., \& Jafri, $\mathbf{W}$. (2012). Frequency of poor quality of life and predictors of health related quality of life in cirrhosis at a tertiary care hospital Pakistan. BMC research notes, 5,
https://doi.org/10.1186/1756-0500-5-446

3. Janani, K., Jain, M., Vargese, J., Srinivasan, V., Harika, K., Michael, T., \& Venkataraman, J. (2018). Health-related quality of life in liver cirrhosis patients using SF-36 and CLDQ questionnaires. Clinical and experimental hepatology, 4(4), 232-239. https://doi.org/10.5114/ceh.2018.80124

4. Souza, N. P., Villar, L. M., Garbin, A. J., Rovida, T. A., \& Garbin, C. A. (2015). Assessment of health-related quality of life and related factors in patients with chronic liver disease. The Brazilian journal of infectious disease: an official publication of the Brazilian Society of Infectious Diseases, 19(6), 590-595. https://doi.org/10.1016/j.bjid.2015.08.003

5. GBD 2017 Cirrhosis Collaborators (2020). The global, regional, and national burden of cirrhosis by cause in 195 countries and territories, 19902017: a systematic analysis for the Global Burden of Disease Study 2017. The lancet. Gastroenterology \& hepatology, 5(3), 245-266. https://doi.org/10.1016/S2468-1253(19)30349-8

6. WHO (2018). Liver cirrhosis $(15+)$, agestandardized death rates by country. Nguôn tài liệu https://apps.who.int/gho/data/view.main.53420

\title{
KẾT QUẢ ĐIỀU TRI ENDOXAN TĨNH MACH LIỀU CAO Ở BÊNH NHÂN LUPUS BAN ĐỎ HÊ̂ THÔNG ĐợT CẤP CÓ TỔN THƯƠNG THẦn CÓ THAY THẾ HUYẾT TƯƠNG TẠI KHOA THẬN TIẾT NIỆU BỆNH VIỆN BẠCH MAI
}

\author{
Trần Bích Ngọc ${ }^{1}$, Đỗ Gia Tuyển ${ }^{1,2}$, Nguyễn Gia Bình ${ }^{3}$
}

\section{TÓM TẮT}

Mục tiêu: Đánh giá thay đổi lâm sàng, xét nghiệm sau điều trị endoxan tĩnh mạch liêu cao 6 tháng ở bệnh nhân (BN) lupus ban đỏ hệ thống (LBĐHT) đợt cấp có tổn thương thận kết hợp thay thế huyết tương. Đối tượng và phương pháp nghiên cứu: 55 BN LBĐHT được điêu trị từ 10/2014-6/2018 tai khoa Thân Tiết niệu bênh viên Bach mai. Sau khi thay thế huyết tương 3 lần $\mathrm{BN}$ được điều trị bằng endoxan truyền tĩnh mạch liều cao $500 \mathrm{mg} / \mathrm{kg} / \mathrm{m}^{2} \mathrm{da}$ hàng tháng trong 6 tháng, kết hợp methylprednisolon. Phương pháp nghiên cứu: mô tả, tiến cứu. Kết quả: Sau điều trị: điểm SLEDAI giảm từ 24,1 45,5 xuống $11,5 \pm 6,1 ; p<0,00001$. Nồng độ kháng thể kháng DsDNA giảm từ $163,9 \pm 131,8$ xuống $75,3 \pm 76,1$

\footnotetext{
${ }^{1}$ Trung tâm Thận Tiết niệu-lọc máu, Bệnh viện Bạch mai ${ }^{2}$ Trường Đại học Y Hà Nội

${ }^{3}$ Bênh viện Bạch Mai

Chịu trách nhiệm chính: Trân Bích Ngọc

Email: tranbichngoc76@gmail.com

Ngày nhận bài: 5.5.2021

Ngày phản biện khoa học: 25.6.2021

Ngày duyệt bài: 5.7.2021
}

$\mathrm{IU} / \mathrm{ml} ; \mathrm{p}=0,005$. Về thân: mức loc câu thân (MLCT) đã tăng tứ $27,6 \pm 20,6$ lền $67,6 \pm 37,7 \mathrm{ml} / \mathrm{p} / 1,73 \mathrm{~m}^{2} \mathrm{da}$; $p<0,0001$. Đáp ứng thân hoàn toàn là $10,9 \%$, đáp ứng không hoàn toàn là 49,1\%. Kết luận: đây là phác đồ điêu trị mang lại hiệu quả, an toàn và có thể áp dụng trong điều kiện của nước ta.

Tư khóa: lupus, thay thế huyết tương, endoxan

\section{SUMMARY}

THE OUTCOME OF CONCURRENT

TREATMENT WITH 6-MONTH HIGH DOSE INTRAVENOUS ENDOXAN AND PLASMA

EXCHANGE FOR LUPUS NEPHRITIS FLARE IN NEPHRO-UROLOGY DEPARTMENT,

\section{BACH MAI HOSPITAL}

Objectives: evaluate the change in clinical, laboratory in patients with lupus nephritis flare to concurrent treatment with plasma exchange and high dose intravenous endoxan. Participants: 55 patients with lupus nephritis flare were given treatment from October 2014 to June 2018 in Bach mai Hospital. The standard regimen includes 3 sessions of plasma exchange, followed by monthly intravenous endoxan $\left(500 \mathrm{mg} / \mathrm{m}^{2} \mathrm{BSA}\right)$ for 6 months in combination with prolonged steroid. Methods: prospective study 